\title{
La investigación de las prácticas sociales y culturales de justicia
}

ROSEMBERT ARIZA SANTAMARÍA*

Fecha de recepción: 24 de mayo de 2005

Fecha de aprobación: 14 de julio de 2005

\section{RESUMEN}

Este artículo da cuenta tanto del trabajo de investigación como de las reflexiones teóricas y metodológicas que ha enfrentado el Centro de Investigaciones de la Facultad de Derecho de la Universidad Santo Tomás y por supuesto las dificultades de la propia práctica investigativa. Recoge sucintamente el acervo experiencial del ejercicio de la docencia - investigación, y presenta además un panorama bastante robusto de las teorías y metodologías precisando algunos de los desafíos que enfrenta la investigación sociojurídica en la actualidad.

\section{PALABRAS CLAVES}

Investigación, pluralismo jurídico, resolución alternativa de conflictos

\section{ABSTRACT}

This article relates the investigation task and the theoretical and methodological reflections that had faced the Investigation Center and the typical difficulties of the investigation practice. It picks up briefly the experiences of the practice of teaching connected with investigation and presents a description of the theories and methodologies specifying some of the challenges that faces the socio juridical investigation at present.

* Profesor de Sociología Jurídica de la Facultad de Derecho de la Universidad Santo Tomás y Director del Centro de Documentación de Solución de Conflictos. 


\section{KEY WORDS}

Investigation, juridical pluralism, alternative conflicts solution

\section{Introducción}

En los cinco años que llevo trabajando con el Centro de Investigaciones de la Facultad de Derecho, son múltiples las reflexiones que hemos abordado docentes y estudiantes sobre el tema que da título a este artículo. Algunos semestres con mayor intensidad que en otros. Lo que presento a continuación es parte de estas disquisiciones con los primeros, lo mismo que con el semillero de investigación que actualmente coordino.

En primer lugar, y a modo de introducción, parto del debate investigación y conocimiento, donde, por supuesto, no pretendo zanjar la discusión, sino, por el contrario, mirar el horizonte general y dar algunos elementos que nos ayuden a orientar nuestro quehacer investigativo en este campo. En segundo lugar, abordaré lo concerniente a los paradigmas del estudio de lo jurídico en las comunidades tradicionales, así como los enfoques más recurrentemente usados en la investigación sobre estos temas. Finalmente, presento unas perspectivas de trabajo investigativo a partir de la experiencia de la investigación asistida y en particular desde el tema Acceso a la Justicia, línea que me corresponde desarrollar en el Centro de Investigaciones.

La pretensión final es profundizar en los marcos teóricos y metodológicos existentes e iniciar las reflexiones pertinentes acerca de estos temas, los cuales, parece ser, ocuparán prioritariamente nuestra atención en los próximos años.

\section{Investigación-creación o razón}

"La investigación no es una construcción de la realidad, es una visibilización de nuestra comprensión". Basándome en esta afirmación, podría, "prima facie", sostener que la investigación y el conocimiento tienen el mismo cometido. Sin embargo, existe una pregunta que antecede a todo este debate: ¿Qué significa la comprensión? Morin, responde: "...Se puede entender en virtud de los dos polos del conocimiento: la explicación y la comprensión. La explicación es el modo de conocimiento racional que considera lo que se quiere conocer como un objeto, como la instrumentalización de la cosa vital, en que finalmente se puede conocer el objeto con objetividad. La comprensión es el modo de conocimiento de un sujeto por otro sujeto que contiene en sí mismo la empatía, la identificación, la proyección; es decir, un modo de conocer inmediato para acceder a la afectividad, el sentimiento, el llorar, el creer, el amar" (Morin, 1988: 36).

En consecuencia el conocimiento significa la unión de la comprensión y de la explicación, la unión de los modos de conocer y no la exclusión del otro.

A pesar del conformismo cognitivo (Morin) o del llamado pensamiento blando y flexible adaptado a la sociedad de los medios de comunicación (Castoriadis), existen trabas innegables que gobiernan y organizan el conocimiento. Las ideas y el pensamiento se agitan y permiten la evolución del conocimiento, la visibilización de nuevas maneras de ver la realidad. En otras palabras, la diversidad 
de puntos de vista rompe el llamado "imprinting" cultural haciendo posible en el dominio cognitivo el encuentro de diferentes comprensiones.

Maturana, por su parte, señala que la realidad no es una experiencia sino un argumento dentro de una explicación, que la realidad surge como una proposición explicativa de nuestra experiencia, de las coherencias operativas de nuestra vida cotidiana y de nuestra vida técnica. $Y$ agrega que las explicaciones científicas no explican un mundo independiente, explican la experiencia del observador, u observadora, y ese es el mundo que él o ella viven.

Con ese argumento convincente podríamos inferir que la realidad no es más que lo que podemos comprender, lo demás no existe. Sin embargo, por esta vía es factible caer en la proclama final Hegeliana "Todo lo que es racional es real y todo lo que es real es racional".

Creo que el racionalismo per se está agotado como la misma modernidad, sin desconocer su logro final: hacernos entender que no existe ningún fundamento cierto para el conocimiento y que este contiene sombras, zonas ciegas, agujeros negros.

Investigar y conocer son una necesidad humana de llenar estos vacíos (llámese ignorancia); son un impulso natural a entender la propia existencia pese a que hoy pisemos el lodo, lo no sólido, la no certeza. Pero mientras pensemos tenemos la posibilidad de problematizar y aquí se inicia el conocimiento y la investigación.

Coincidimos todos en que la investigación y el conocimiento deben ser humanos. El riesgo de la comprensión es que pueden cometerse muchas equivocaciones, mientras que el riesgo de la explicación es que pierda el sentido de la realidad del ser humano como humano.
Por lo tanto, investigación y conocimiento son una creación humana, son un sentido de ver y entender la vida articulados a la estructura cultural, a la organización social, a la propia historia humana que es también creación.

Lo anterior, dilucida de alguna manera el por qué del conocer e investigar. Quedaría pendiente el para qué de la investigación y el conocimiento. Frente a esto, solo tendría que decir que el Occidente moderno se debate entre dos posibilidades:

Por un lado, un proyecto de autonomía individual y colectiva en lucha por la emancipación del ser humano, tanto intelectual y espiritual, como afectiva. De otra parte, un proyecto capitalista de expansión ilimitada de un pseudo-dominio, pseudoracional, que desde hace tiempo dejó de concernir sólo a las fuerzas productivas y a la economía, para devenir en proyecto global de dominación total de los substratos físicos, biológicos, psíquicos, sociales y culturales de la humanidad.

¿Para qué, por tanto, la investigación y el conocimiento? Precisamente para salir de esta encrucijada en la cual se debate la especie humana.

\section{La investigación de los sistemas jurídicos paralelos}

El pionero de la sociología jurídica, Antonio Pigliaru, realizó en 1959 una investigación que se proponía estudiar las costumbres de las comunidades asentadas en la región montañosa de la Cerdeña (comunidad de Barbogia) para determinar el ordenamiento jurídico que los regía por antigua tradición, con el fin de comparar tal ordenamiento espontáneo, no escrito, con el ordenamiento positivo italiano vigente en dicha región. Esta investigación de corte socio jurídico, al igual que la realizada por el jurista danés Verner Goldsschmidt, en Groenlandia, con el objeto de codificar el derecho 
penal consuetudinario local, da cuenta de cómo, a mitad del siglo XX, los investigadores echaron mano de otras disciplinas como la antropología cultural y el derecho comparado con el fin de dilucidar el encuentro entre sistemas jurídicos y culturas jurídicas distintas, que por ninguna razón desconocen elementos muy complejos como la "aculturización" y la "modernización" (Treves, 1988); a más de ello no es posible olvidar los fenómenos particulares de descolonización que en el tercer mundo, y en particular en Colombia, -que con el derecho español nos impuso una impronta de concomitancia jurídica y un legado imposible de obviar a la hora de realizar trabajos de investigación en este campo-.

Por esta vía, por supuesto, aparecen los estudios sobre "pluralismo jurídico", línea que ha cobrado gran importancia y que constituye un campo necesario de exploración en nuestro país, no sólo por la existencia de jurisdicciones especiales autónomas ${ }^{1}$ sino por las posibilidades de visibilizar sistemas jurídicos comunitarios que se manifiestan en numerosas zonas urbanas y rurales del país.

El concepto de "pluralismo jurídico", en su acepción amplia, ha traído consigo un debate en torno a la definición del derecho y al lugar particular que éste ocupa como derecho del Estado en los escenarios plurales.

Formulaciones recientes demuestran que no basta con hablar de sistemas jurídicos interconectados, sino que es necesario analizar cómo éstos se construyen mutuamente. Es decir, estudiar como el derecho estatal penetra y reconstruye los órdenes sociales por medios simbólicos y coercitivos; cómo se genera la resistencia hacia ellos, pero también, como el derecho estatal es, a su vez, modificado. Además, señala Sally Merry, el derecho estatal también puede ser constituido por otros órdenes nor- mativos, como en el caso del derecho trasnacional e internacional; en este sentido, el derecho estatal en sí mismo es plural.

En un sentido similar, el concepto de "interlegalidad" planteado por Boaventura Santos de Sousa critica la teoría del derecho y ofrece nuevas perspectivas para comprender la problemática del pluralismo jurídico. Distanciándose del pluralismo jurídico tradicional que propició la visión dualista de los sistemas legales coexistiendo en un mismo campo social, Santos plantea una concepción posmoderna del pluralismo jurídico que define como "una concepción de diferentes espacios legales superimpuestos, interpenetrados y mezclados en nuestras mentes como en nuestras acciones, en ocasiones de saltos cualitativos o crisis oscilantes en nuestras trayectorias como en la rutina de los eventos cotidianos. Nuestras vida está constituida por una intersección de órdenes legales, esto es la interlegalidad" (Santos, 1985: 299).

El concepto de interlegalidad ofrece efectivamente una mirada diferente, de gran potencialidad para comprender las conexiones diferenciadas de normas y su expresión simbólica en diferentes niveles, que van de lo local a lo internacional pasando, desde luego, por lo nacional. Para Santos, la interlegalidad es la manifestación fenomenológica del pluralismo jurídico, concepto que, como lo digimos, tiene gran influencia en los estudios contemporáneos sobre el tema.

Sin embargo, es poco lo que se ha recorrido en este camino, y se requiere avanzar en tal sentido. No obstante, debemos aclarar y aclararnos si efectivamente contamos con dichos sistemas jurídicos, e igualmente precisar la categoría de pluralismo que más se aplica a nuestro contexto multicultural, multiétnico y plurilegal. Son pues, categorías que hoy deben ser revaloradas con el propósito de pro-

1 Me refiero a la Jurisdicción Especial Indígena y a la Jurisdicción Especial de Paz 
fundizar en las características y especificidad de lo que seguimos denominando como "otras prácticas de justicia".

\section{La investigación en la resolución de conflictos}

El proceso de disputa se convirtió en el centro de atención de los teóricos e investigadores de esta línea, destacándose el interés por las estrategias de los actores sociales en el sentido de analizar los modos como se confrontan, manejan y resuelven los conflictos.

Esta área de investigación, al decir de Vicenzo Ferrari, "ha nacido con el intento de establecer una línea común entre el estudio típicamente antropológico de los mecanismos resolutorios de conflictos en las sociedades preindustriales 0 , como se solía decir, "primitivas", y el estudio típicamente sociológico de las instituciones procesales en las sociedades industriales modernas" ${ }^{\prime 2}$.

A partir del Ilamado movimiento de desjudicialización y con la incorporación de los llamados MASC (Mecanismos Alternativos de Solución de Conflictos) y de la implementación de figuras como la mediación, conciliación, amigable composición y otras, aparece la llamada justicia informal, que se desarrolla por fuera de las instituciones judiciales estatales en principio, ya que el Estado mantiene su interés en controlarlas, reglamentarlas e institucionalizarlas.

Lo que tenemos hoy que compartir como investigación es el desarrollo de estas figuras, su efectividad en la resolución de causas menores, la aceptación de imaginarios sociales sobre el quehacer de estos resolutores de pequeños conflictos, las técnicas y formas de operar de dichos mecanismos y los beneficios en términos de descongestión judicial 0 acceso a la justicia.

Dejando de lado las búsquedas acerca de un derecho basado en la equidad o la revisión del llamado derecho espontáneo, y en el mismo sentido, el estudio de estos "operadores" como movimiento social estructurado o no, básicamente los estudios realizados en gran parte por los estudiantes de nuestra Facultad se enmarcan en estos temas y la mayor parte de ellos apelan al marco teórico de la clásica resolución de conflictos, que es, por demás, el más pobre de todos los conocidos, e incluso para muchos autores en este campo carece de sustrato teórico.

Por ello es necesario revisar otros paradigmas que pueden complementar y fundamentar los trabajos que estamos desarrollando en nuestra alma mater.

\section{Los paradigmas}

Los antropólogos que se han interesado por el estudio de lo jurídico en las sociedades no occidentales han debatido acerca de las distintas posiciones implicadas en los enfoques teóricos y metodológicos de la investigación. John Comaroff y Simon Roberts (1981) han sistematizado esta discusión definiendo dos grandes paradigmas que conciernen a los modos de abordar estas indagaciones.

Por un lado, el que considera que se debe proceder al conocimiento de las normas (paradigma "normativo"), y por otro, el que presta atención a los procesos sociales y jurídicos (paradigma "procesual") $)^{3}$.

Dentro del paradigma normativo, siguiendo a Sierra y Chenaut en la cita que hacen de Llewelyn y

2 FERRARI, Vicenzo. “Diritto e Dispute: osservazioni empiriche in una piccola comunita”. En: Sociologia del Diritto, 1982, pp. 34 y ss.

3 En SIERRA, María Teresa y CHENAUT, Victoria. Los debates recientes y actuales de la antropología jurídica: las corrientes anglosajonas en antropología jurídica: perspectivas socioculturales en el estudio del derecho. Esteban Krtz (Ed.), Antropos, Universidad Autónoma Metropolitana, España, 2002. 
Hoebel (1949), consideran que la unidad de análisis debería ser el estudio de casos de disputas a través de los cuales es posible indagar las normas que prevalecen en las decisiones tomadas por las autoridades y que son estimadas como jurídicas. En un libro posterior, Hoebel se refirió al carácter inductivo de su método, a través del cual se accedía a las normas de derecho primitivo por medio del análisis de un variado numero de casos de disputas; destacó que el método permitía conocer los sistemas normativos desde el interior de sus dinámicas de funcionamiento, por lo que era más productivo y confiable, ya que en el análisis de las disputas se podía encontrar cuáles eran las normas vigentes de una sociedad. Su postulado de que "el derecho divorciado de su matriz cultural carece de sentido", remite a concebir el derecho como un aspecto de la cultura y la sociedad de un pueblo, $y$ a reconocer la necesidad de tomar en consideración que un estudio antropológico del derecho debe estar fundamentado en el conocimiento de la etnografía general de la sociedad de referencia.

En general, los escritores que son ubicados en esta perspectiva ponen el acento en el estudio de las instituciones y conciben las disputas como señales de desviación, ya que otorgan fundamental importancia al mantenimiento del orden social; además estiman que las sociedades necesitan tener autoridades centralizadas para hacer valer el derecho y establecer códigos normativos. El paradigma normativo por supuesto se encuentra vinculado a la concepción del positivismo jurídico formalista.

Los teóricos del paradigma procesual establecieron que en este enfoque el conflicto y las disputas constituyen parte de procesos sociales extensos, por lo que las disputas no son concebidas como señales de desviación, como ocurre en el paradigma normativo. De esta manera, el abordaje metodológico debe centrarse en los procesos de disputa, en las interacciones entre los litigantes, teniendo en cuenta los diferentes tipos de relacio- nes sociales a partir de los cuales surge la disputa y el contexto social total de la misma. Por lo tanto, la atención analítica se preocupó no tanto por indagar acerca de las autoridades judiciales, sino por los litigantes, sus motivos, argumentaciones y estrategias y por las negociaciones que se establecen entre las partes. El conflicto y el proceso de disputa se convirtieron en el centro de atención, destacándose el interés por las estrategias de los actores sociales, en el sentido de analizar los modos como se resuelven, manejan y confrontan los conflictos. En este aspecto el proceso de resolución de disputas es percibido como un marco conceptual y organizacional para la negociación competitiva, la transacción y el compromiso.

En síntesis, se destaca para los autores de este paradigma la consideración de que los procesos judiciales son parte inevitable de la vida social.

Sin embargo, hoy se debe insistir en estudiar el carácter productivo del derecho vigente en toda sociedad y retomar la propuesta Gramsciana en torno a la "hegemonía" y "resistencia" para estudiar la manera en que el derecho es un referente central de legitimación de saberes y poderes, para garantizar un determinado consenso, pero también para mostrar que desde la cotidianidad se confronta a esos poderes y se genera la resistencia.

Este paradigma, denominado de la historia y el poder, es sin duda el referente teórico que debe abocar el estudio de las prácticas sociales de justicia comunitaria, entre otras razones por los siguiente:

- Permite mirar los nuevos ordenamientos jurídicos a los que se apela desde los espacios locales para confrontar límites impuestos en los ámbitos nacionales.

- Permite relacionar la vida cotidiana de la conflictividad social con una visión de los procesos hegemónicos en los que se insertan estas sociedades. 
- Permite establecer las condiciones materiales de existencia y realizar una anatomía del poder y sus incrustaciones en las producciones culturales.

Finalmente, mencionaré brevemente en este acápite dos teóricos que aportan y que son en últimas los teóricos de mayor influencia en el desarrollo de la sociología del derecho en las dos últimas décadas en América Latina.

El primero, Michel Foucault, quien centró su obra en el estudio de las relaciones de poder, los ámbitos del saber, la ética de la existencia y las políticas de verdad en Occidente, planteando tres líneas de análisis relacionadas entre sí: el poder, el saber y la subjetividad.

Según Deleuze, Foucault fue el pionero en el análisis de la subjetivación y sus consecuencias, como en el estudio de la historia de los delitos y las penas, pronosticando una nueva era de controles no conocida, con la preocupación del diagnóstico y solución de problemas presentes.

Foucault abordó la noción de poder en torno a dos conceptos, el conocimiento y el cuerpo. El conocimiento que se ejerce sobre el cuerpo para el mejor ejercicio del poder sobre él. Estudió la organización de las relaciones de poder y sus técnicas, lo analizó como aquello omnipresente que produce acciones en los individuos y canaliza sus facultades, y a éstos como instrumentos mismos de ese poder. Buscó la respuesta a dos grandes preguntas, la del saber y la del poder, y su búsqueda dió por resultado la construcción de dos propuestas metodológicas: el método arqueológico y el genealógico.

Trabajó las posibilidades productivas de la norma, como cuando ésta limita, pero también escribió sobre su inmanencia; arguyó que concebir la inmanencia de la norma equivale a cancelar su opción represiva y nos lo demostró con la Historia de la sexualidad y las leyes constitutivas del deseo.

Foucault consideraba las prácticas judiciales como prácticas sociales y la existencia de dos historias de la verdad. Afirmaba que las prácticas judiciales muestran cómo los hombres arbitran daños, responsabilidades, castigos y reparaciones, con formas que definen subjetividades, saberes y relaciones entre el hombre y la verdad. Señala que el derecho penal fue el lugar de origen de algunas formas de verdad, porque la indagación es una forma de verdad; escribió sobre la existencia de tres nuevos instrumentos que en la sociedad moderna se encuentran en la base de la norma: la sanción, la vigilancia y el examen.

El segundo es Pierre Bourdieu, sociólogo que abandonó el término sociedad y en su lugar trabajó las categorías de campo y de espacio social.

El campo jurídico, como insiste Bourdieu en "Elementos para una sociología del campo jurídico", es una parte del espacio social en la que los distintos agentes pelean por el monopolio para decidir qué es el derecho; es el lugar donde abogados, jueces, profesores, personas que ocupan una posición con respecto al campo en general del poder y al interior de cuyas profesiones se reproduce también, se lucha, compite entre sí, para determinar cual es la autoridad que permite, en última instancia, decir qué es derecho.

En un trabajo reciente dos autores Colombianos, García y Rodríguez (2003), usando la teoría de Bourdieu, proponen la consolidación de los estudios jurídicos críticos, haciendo un uso bastante sugerente de la noción de campo jurídico y del esquema analítico del profesor Boaventura de Sousa. En este trabajo la noción de Bourdieu permite tener una visión de las prácticas jurídicas que no sólo supera las visiones formales del derecho, sino que además permite interpretar fecundamente 
muchas de sus dinámicas, como las interacciones de actores por controlar ciertos privilegios dentro de determinados contextos estructurales.

Este ensayo ha puesto en discusión los problemas de los temas y las condiciones epistemológicas alrededor de los cuales sería posible la construcción de una sociología jurídica en América Latina.

Destaco de este ensayo, igual que el recorrido por la visión empirista o descriptiva del derecho, la denominada corriente de "derecho y desarrollo", las posiciones constructivistas y por supuesto la crítica jurídica, que es el acervo sobre el cual se mueve una porción importante de teóricos en el país.

Entre todos estos paradigmas, enfoques, líneas teóricas y metodológicas se encuentran inmersos los estudios de las prácticas sociales y culturales de justicia, con dos dificultades adicionales además de las ya analizadas por varios autores. Una, la referida al problema de investigación y la segunda al objeto de estudio o también llamado por algunos como la unidad de análisis de este campo particular "Justicia y Sociedad", como se define nuestra línea de investigación y nuestro grupo de investigación.

El campo de las prácticas sociales y culturales de la justicia, nos da múltiples posibilidades para abordar problemas jurídicos reales y definir de manera cierta un objeto de estudio en el cual poder concentrar nuestros esfuerzos investigativos.

A manera de reflexión final quiero plantear la realización de unas tareas inmediatas que nos permitan consolidar nuestro centro de investigaciones.

\section{Comunidad académica y perspectiva metodológica}

Si bien es cierto que tenemos avances en el tema de investigación en la Facultad, estamos en mora de consolidar los grupos de investigación y de rea- lizar los intercambios con otros centros que tengan mayor trayectoria en el tema, dentro y fuera del país. La constitución de una comunidad académica en el tema pasa por estos dos aspectos como mínimo: la definición de un grupo de docentes que de manera permanente se dedique exclusivamente a la investigación y, dos, que cuenten con los recursos necesarios para realizar la investigación, de tal suerte que puedan entre otras cosas asistir a los espacios y eventos donde se encuentra la comunidad académica para intercambiar, reconocer y, porqué no, avalar lo realizado por sus colegas.

En este campo del derecho y la sociedad existe una comunidad académica prolífica, que viene realizando diferentes trabajos en toda América Latina. Es hora de que nuestros docentes y estudiantes inicien su inmersión en dicha comunidad. Lo contrario es el parroquianismo de cafetería, que no deja más que el sabor de tibias monografías de grado que llenan los anaqueles de la biblioteca de nuestra Facultad.

En cuanto a la perspectiva metodológica, hemos echado mano del llamado pluralismo metodológico, por lo menos en lo realizado hasta la fecha. Ésa es la concepción. No obstante, como lo propusiéramos semestres atrás, se requiere revisar los enfoques metodológicos y determinar si existen coincidencias para ser aplicadas en las diferentes líneas de investigación.

Este tema no sería de interés si sólo nos circunscribiéramos a realizar investigación empírica, pues es el método inductivo el que prevalece en los trabajos de investigación asistida, como el método cualitativo y los dos combinados son esencialmente los más usados en los trabajos en la línea de acceso a la justicia.

En algunos trabajos, muy pocos por cierto, hemos trabajado el método dialéctico comparativo histórico y analítico. 
Existen una serie de generalidades que constituyen normas básicas del trabajo investigativo. Para finalizar, quiero referirme a una de ellas, la llamada creatividad y la innovación.

Son demasiados los lugares comunes en el estudio del derecho. La investigación es la oportunidad de problematizar el conocimiento dado, las fórmulas infalibles, la reproducción asistemática del discurso jurídico añejo y la "repetición de la repetidera". Debemos suscitar en nuestra comunidad tomasina, tanto en docentes como estudiantes, el mirar otros temas diferentes a los ya trajinados por la dogmática jurídica

El campo de las prácticas sociales y culturales de justicia es una veta sin explotar. No dejo de sorprenderme al ver cómo las generaciones actuales de estudiantes son más proclives a estos temas y a aquellos que les permitan dar rienda suelta a la castrada creatividad.

\section{Bibliografía}

BARCELONA, Pietro (1990). Postmodernidad y comunidad. El regreso a la vinculación social. Trotta, Madrid.

BERGALLI, Roberto (1989). El derecho y sus realidades. Investigación y enseñanza de la sociología jurídica. Ppu, Barcelona.

(1998). “¿De cuál derecho y de cuál control social se habla?". En: BERGALLI, Roberto (Ed.). Contradicciones entre derecho y control social. Bosch- Goethe Institut, Barcelona.

BOURDIEAU, Pierre (2000), (A). Poder, derecho y clases sociales. Desclée de Brower, Bilbao.

(2000), (B). "Elementos para una sociología del campo jurídico". En: BOURDIEAU, Pierre \& GUNTHER, Teubner. La fuerza del derecho (Trad. Carlos Morales de Setién Revina). Siglo del Hombre Editores, Bogotá.
CASTORIADIS, Cornelius (1998). El ascenso de la insignificancia". Frónesis, Cátedra Universidad de Valencia.

CORREAS, Oscar (1994) (A). "La teoría general del derecho frente al derecho indígena". En: Crítica Jurídica, No. 14. México: Universidad Autónoma de México.

1994 B, “La teoría general del derecho y el derecho alternativo", en El Otro Derecho, Vol. 5, No. 3, Bogotá: Ilsa.

1995, INTRODUCCIÓN A LA SOCIOLOGÍAJURÍDICA, Bosch, Barcelona.

1997, “Una Concepción sociológica del Derecho", en CASTAÑEDA, Fernando y otro, EL USO Y LA PRÁCTICA DE LA LEY EN MÉXICO, Porrúa, MéxiCO.

SANTOS, Boaventura de Sousa, 1985. "On modes of production of low and social power". En: International Journal of the Sociology of Law, 1985 (13), 299 ss.

Yves, DEZALAY \& TRUBEK, David 1994. "La reestructuración global y el derecho". En: Pensamiento Jurídico, No. 1, Bogotá: Universidad Nacional de Colombia.

FERRARI, Vincenzo, 2000. Acción jurídica y sistema normativo. Introducción a la sociología del derecho, Trad. Andrea Greppi, Madrid: Universidad Carlos III de Madrid - Dykinson.

FOUCAULT, Michelle, 1978. Vigilar y castigar. El nacimiento de la prisión. México: Siglo XXI. 1995. La Verdad y las formas jurídicas, Trad. Del Portugués Enrique Lynch, Barcelona: Gedisa.

1988. Un diálogo sobre el poder, trad. Miguel Morey, Madrid: Alianza. 
1992, La microfísica del poder. Madrid: Ediciones de la Piqueta.

GARCÍA, Mauricio y RODRÍGUEZ, Cesar, 2003. En: Derecho y Sociedad en América Latina. Un debate sobre los estudios jurídicos críticos, ILSA.

MORIN, Édgar. "El pensamiento complejo". Entrevista con José Malaver. En: Ensayo y Error, No 4, abril de 1998.

SIERRA, M. Teresa. 1992, “Conflicto y Transacción entre la ley y la costumbre indígena". En: Crítica
Jurídicia, No.11, México: Universidad Autónoma de México.

TREVES, Renato, 1988. Sociología del derecho. Orígenes, investigaciones, problemas. Trad. Manuel Atienza y otros, Barcelona: Ariel.

WOLKMER, Antonio, 1991. "Pluralismo jurídico, movimientos sociales y prácticas alternativas". En: EI Otro Derecho, No. 7, Bogotá: Ilsa. 